\title{
Prolonged Cold Storage Diminishes the 5-Hydroxytryptamine- and Potassium Chloride-Mediated Contractions of Rat Thoracic Aorta
}

\author{
H. ZAFER GÜNEY ${ }^{1}$ and Z. SEVIM ERCAN ${ }^{1}$ \\ ${ }^{1}$ Department of Pharmacology, Gazi University Medical School, Besevler, Ankara, Turkey
}

\begin{abstract}
Hypothermic preservation of the organ for transplantation causes vascular damage; therefore, the preservation of vascular function is important for the organs to function correctly after transplantation. The aim of the present study is to evaluate the influence of prolonged cold storage (72 hours) on vascular responses to 5-hydroxytryptamine $(5-\mathrm{HT})$ and potassium chloride $(\mathrm{KCl})$, each of which causes receptor-dependent and receptor-independent contractions, respectively. We also examined the protective roles of superoxide dismutase (SOD), L-arginine, the precursor of nitric oxide, iloprost, a synthetic analogue of prostaglandin $I_{2}$ with vasodilator functions, or endothelium removal for vascular responses. Endothelium-intact rings were prepared from the rat thoracic aorta, and stored at $4^{\circ} \mathrm{C}$ for up to 72 hours in Krebs solution alone or Krebs solution that contains SOD, L-arginine or iloprost. The vascular responses were investigated daily. The Analysis of Variance (ANOVA) followed by Dunn test was used for statistical analysis. Being kept in cold in Krebs solution diminished the vascular responses to $5-\mathrm{HT}$ and $\mathrm{KCl}$. The presence of SOD in Krebs solution successfully prevented the decline in these responses, while iloprost or L-arginine partially restored them. In the endothelium-denuded rings, the 5-HT-induced contraction remained protected after 72 hours, whereas the $\mathrm{KCl}$-induced contraction was partially restored. These results indicate that cold preservation declines the $5-\mathrm{HT}$ and $\mathrm{KCl}$-induced vascular responses, which can be partially prevented by iloprost or L-arginine, and can be restored by endothelium removal or SOD. Therefore, superoxide anion and endotheliumderived factors contribute to the decline in the contracting function of the aorta during prolonged cold storage. — cold storage; potassium; 5-hydroxytryptamine; rat; aorta.
\end{abstract}

Tohoku J. Exp. Med., 2009, 217 (2), 155-161. 두 2009 Tohoku University Medical Press

The vascular damage caused by hypothermic preservation is important in the short-term and long-term outcome of organ preservation, and the protection of vascular tissues is an important issue for tissue viability in transplantation and cardiovascular research (Knes et al. 2005). Among the two methods used, prolonged cold storage at $4^{\circ} \mathrm{C}$ (Török et al. 1993) preserves vascular function for several days while it is possible to conserve vascular reactivity for longer periods by storing tissues at -70 or $-190^{\circ} \mathrm{C}$ using cryopreservative methods (Hunt et al. 1994).

Cold storage is essential during the interval between harvesting and transplantation, and it has been shown that cold storage induces changes in the response of tissues to various vasodilator and vasoconstrictor agents. The most consistent alterations are the degeneration of the adrenergic nerve endings (Török et al. 1993) and the degeneration of endothelial cells (Hansen et al. 1994; Török et al. 1993). The endothelium in human hearts has been shown to become detached following a storage period of 3 to 8 hours at $4^{\circ} \mathrm{C}$ (Billingham et al. 1980). However, in rabbit aorta (Török et al. 1993) and in rat lungs (Pickford et al. 1990), the same detachment took 1-4 days.
Contradictory results have been obtained from studies investigating the effect of cold storage on the responses to vasoconstrictor agents. It has been reported that, in canine arteries, which were stored for 24 hours at $6^{\circ} \mathrm{C}$, the responses to $\alpha$-adrenergic agonists and 5-hydroxytryptamine (5-HT) increased (Murphy et al. 1973). However, these responses were not altered following a 3-7 day storage period at $4^{\circ} \mathrm{C}$ (Ito and Chiba 1985; Sinanovic and Chiba 1987a, 1987b). In a rabbit aorta, on the other hand, the $\alpha$-adrenergic agonist-induced contractions were shown to have reduced after 10 days of storage (Shibata et al. 1971). Additionally, it has been shown that potassium chloride $(\mathrm{KCl})$-induced contraction was diminished after cold storage (Sinanovic and Chiba 1987a, 1987b).

The objective of this study was to determine the effects of prolonged cold storage on the responses to 5-HT, a receptor-mediated agonist, and $\mathrm{KCl}$ that causes membrane depolarization and extracellular $\mathrm{Ca}^{+2}$ influx. Since the results with 5-HT are contradictory, we have chosen 5-HT to investigate receptor-mediated responses. The influence of L-arginine, superoxide dismutase (SOD), iloprost, a synthetic analogue of prostaglandin (PG) $\mathrm{I}_{2}$ or deendotheliza-

Received September 12, 2008; revision accepted for publication January 20, 2009.

Correspondence: H. Zafer Güney, Department of Pharmacolog, Gazi University Medical School, Besevler, 06500 Ankara, Turkey.

e-mail: zguney@gazi.edu.tr 
tion on these responses was also investigated to define the underlying mechanisms.

\section{Methods and Materials}

\section{Rat thoracic aorta preparations}

Locally bred male Sprague-Dawley rats weighing 220-300g were used. They were given food and water ad libitum and housed under controlled environmental conditions, including a lighting regimen of 12 hours of light and 12 hours of darkness (lights on 08:0020:00) for at least 2 weeks before and throughout the experiments. The rats were anesthetized with sodium pentobarbital $(30 \mathrm{mg} / \mathrm{kg})$ and killed by exsanguination from the common carotid arteries. The procedures of the ethics committee for the animal experiments in our university were followed. The thoracic aortae were isolated, cleaned of connective tissue and cut into transverse rings of 3-4 mm width.

Only one ring from each rat was used each day. The rings in the control group were functionally assessed in an organ bath immediately after removal from the rats. Thus, the control group represented the maximal possible response for the harvested aortic rings. The rest of the tissues were placed in tubes containing $5 \mathrm{ml}$ of Krebs solution with the following composition $(\mathrm{mM}): \mathrm{NaCl}, 118.1 ; \mathrm{KCl}, 4.7 ; \mathrm{CaCl}_{2}$, 1.3; $\mathrm{NaHCO}_{3}, 25 ; \mathrm{MgCl}_{2}, 0.5 ; \mathrm{NaH}_{2} \mathrm{PO}_{4}, 0.9$; and glucose, 11.0. The storage solution in the tubes was replaced and bubbled with $95 \%$ $\mathrm{O}_{2}-5 \% \mathrm{CO}_{2}$ for 1 minute every day before the tubes were closed, since it has been shown that oxygenation improves tissue preservation (Okada et al. 1995). The tubes were kept at a constant temperature of $4.0 \pm 0.5^{\circ} \mathrm{C}$ in the refrigerator throughout the experiments. After the storage period, the rings were taken for an organ bath study. On the day of the experiment, the aortic rings were mounted between stainless steel wire hooks and suspended under resting tension of $2 \mathrm{~g}$ in 10 $\mathrm{ml}$ organ baths containing Krebs solution, and slowly warmed to $37^{\circ} \mathrm{C}$ and allowed to equilibrate for 1 hour. The Krebs solution was continuously aerated with $95 \% \mathrm{O}_{2}-5 \% \mathrm{CO}_{2}$ and replaced every 15 minutes. The tension was recorded with Grass FT-03 force displacement transducer for isometric force measurements. The removal of the endothelium was accomplished by rubbing the lumen of the vessel with a roughened stainless steel rod.

\section{Experimental protocol \\ Endothelium-intact rings}

In the control group (fresh tissues), tissues obtained from each animal were kept in tubes containing $5 \mathrm{ml}$ of Krebs solution which was changed every 24 hours throughout the experiment and every day one isolated ring from each animal was studied. After the stabilization period, the rings were contracted with increasing concentrations of 5-HT $\left(1 \times 10^{-7}-10^{-4} \mathrm{M}\right)$ and after washing and recovery, a cumulative concentration response curve for $\mathrm{KCl}(5-100 \mathrm{mM})$ was determined. The two dose response curves from each ring were obtained within approximately one and one half hours after the stabilization period. The same procedure was applied to other aortic rings, which were kept at $4^{\circ} \mathrm{C}$ for 24,48 , or 72 hours.

In another group of endothelium intact rings, after obtaining the responses on the first day, the remaining tissues were incubated with 5 $\mathrm{ml}$ of Krebs solution containing L-arginine $\left(1 \times 10^{-3} \mathrm{M}\right)$, superoxide dismutase $\left(\right.$ SOD-300 U/ml) or iloprost $\left(100 \mu \mathrm{g} / \mathrm{ml}=2.7 \times 10^{-4} \mathrm{M}\right)$ and the experiments were performed after 24,48 , or 72 hours.

\section{Endothelial function}

To determine the functional status of the endothelium, the maxi- mum response to $1 \mu 10^{-6} \mathrm{M}$ ACh was obtained daily in both endothelium intact and endothelium denuded preparations which were precontracted by 5 -HT $\left(5 \times 10^{-6}-8 \times 10^{-6} \mathrm{M}\right)$ before obtaining concentration-response curves to $\mathrm{KCl}$ and 5-HT.

In deendothelized preparations, the absence of functional endothelium was assessed by the lack of a relaxant response to $1 \times 10^{-6} \mathrm{M}$ acetylcholine (ACh) in submaximally (70-80\% of maximum contraction) precontracted $\left(5 \times 10^{-6}-8 \times 10^{-6} \mathrm{M}\right)$ rings with 5-HT immediately after the stabilization period, before the concentration dependent responses to $\mathrm{KCl}$ and 5-HT were obtained.

Drugs

The substances used in this study were purchased from Sigma Chemical Co. St.Louis, USA (L-arginine, superoxide dismutase, 5-HT and $\mathrm{KCl}$ ) and Schering AG, Berlin, Germany, D (Iloprost).

\section{Data analysis}

As we used adjacent rings from the same animal on different days, the 5-HT- and $\mathrm{KCl}$-induced contractions were calculated individually as the percentages of the maximum response at time 0 hours (control group). All the data were expressed as means \pm S.E.M. A statistical analysis was performed by using ANOVA followed by the Dunn test, respectively; a $p$ value of $<0.05$ was considered significant.

\section{Responses to 5-HT}

\section{Results}

In the control group, a significant decrease in the contractile responses to 5-HT was observed after being in cold storage for 24 hours. The contractions were almost abolished (average maximum decrease $85 \%$ ) in aortic rings stored for 72 hours (Fig. 1A).

The incubation of the rings with L-arginine $\left(1 \times 10^{-3} \mathrm{M}\right)$ prevented the decrease in the vascular responses to 5 -HT for only 48 hours. The decrease in the average maximum response in rings which had been stored for 72 hours was $50 \%$ (Fig. 1B).

Iloprost $\left(100 \mu \mathrm{g} / \mathrm{ml}=2.7 \times 10^{-4} \mathrm{M}\right)$ partially restored the 5-HT-induced responses particularly at lower concentrations, but was unable to prevent the decline in the responses at higher concentrations. The decrease in the average maximum response following storage for 72 hours was 63\% (Fig. $1 \mathrm{C})$.

In the endothelium-denuded aortic rings, the responses to 5 -HT were not significantly altered after 72 hours (Fig. 1D).

In the endothelium-intact preparations, adding SOD (300 U/ml) to the Krebs solution during cold storage, not only restored the decline in the vascular reactivity to 5-HT completely, but also shifted the concentration-response curves to the left especially in lower concentrations (Fig. 1E).

\section{Responses to $\mathrm{KCl}$}

In the control group, $\mathrm{KCl}$-induced contractions were not significantly altered following storage for 24 hours, but prolonged storage for 72 hours diminished the responses. 

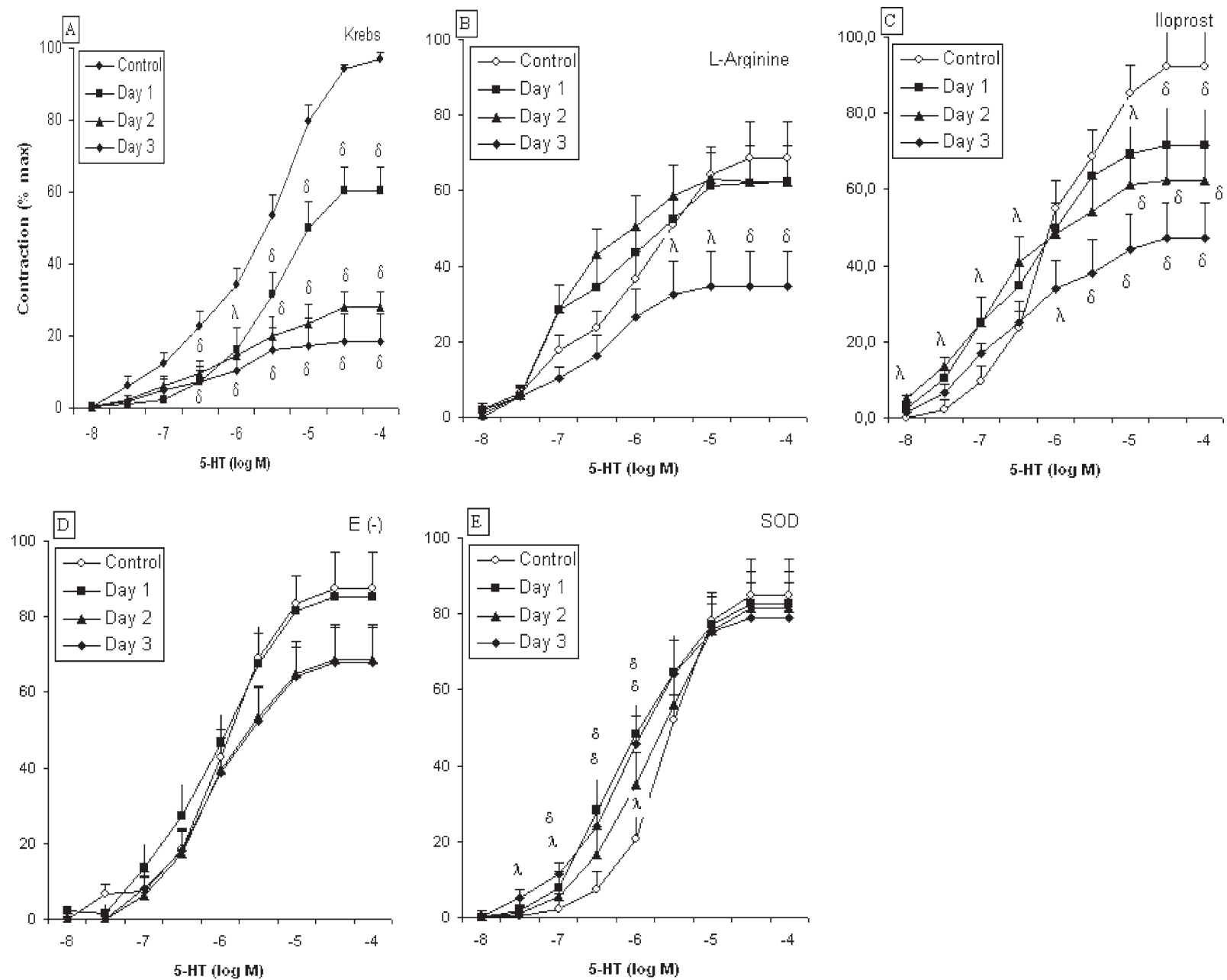

Fig. 1. Receptor dependent contractions induced by 5-hydroxytryptamine (5-HT) in endothelium-intact rat thoracic aorta rings : Rings were stored at $4^{\circ} \mathrm{C}$ in Krebs solution (A), L-arginine (B), Iloprost (C), SOD (E), and endothelium-denuded rings stored in Krebs solution (D). Each point represents the average value of $8-12$ experiments per day and vertical bars show SEM. Statistical analysis was performed by using the Analysis of Variance (ANOVA). $\lambda, p<0.05$ and $\delta, p<$ 0.01: significantly different from control.

The decrease in the average maximum response was $85 \%$ (Fig. 2A), compared with the fresh tissues.

The addition of $\mathrm{L}$-arginine $\left(1 \times 10^{-3} \mathrm{M}\right)$ to the Krebs solution during incubation, prevented the decrease in the responses to $\mathrm{KCl}$ for 48 hours. After 72 hours of cold storage, the average decrease in the maximum response was $55 \%$ (Fig. 2B).

Removing iloprost $\left(100 \mu \mathrm{g} / \mathrm{ml}=2.7 \times 10^{-4} \mathrm{M}\right)($ Fig. 2C) and the endothelium (Fig. 2D) partially restored the decrease in $\mathrm{KCl}$-induced contractions. In both groups, the responses tended to decrease after 48 hours. After being in cold storage for 72 hours in the presence of iloprost or after endothelium-removal, the decrease in the average maximum responses was $63 \%$ and $43 \%$, respectively.

The incubation of the aortic rings with SOD (300 $\mathrm{U} / \mathrm{ml}$ ) afforded significant protection against hypothermiainduced impairment in $\mathrm{KCl}$-induced responses (Fig. 2E). Cold storage for 72 hours in the Krebs solution containing SOD caused a $25 \%$ reduction in the average maximum responses.

\section{ACh induced responses}

The maximum response to ACh $\left(1 \times 10^{-6} \mathrm{M}\right)$ was decreased after 48 hours in the aortic rings stored in Krebs solution. SOD and iloprost was unable to prevent the decline in the ACh-induced responses. Incubation with L-arginine caused a $50 \%$ reduction after 72 hours of storage (Table 1).

\section{Discussion}

Harvested organs are generally transplanted using the immediate blood supply and therefore the functional preservation of the vessels is essential (Corner et al. 2003). The present study demonstrates that $\mathrm{KCl}$ and 5-HT induced contractions in an isolated rat thoracic aorta diminish following a storage period of between $24-72$ hours at $4^{\circ} \mathrm{C}$. These findings are inconsistent with the previous reports in canine coronary artery which showed that the responses remained 

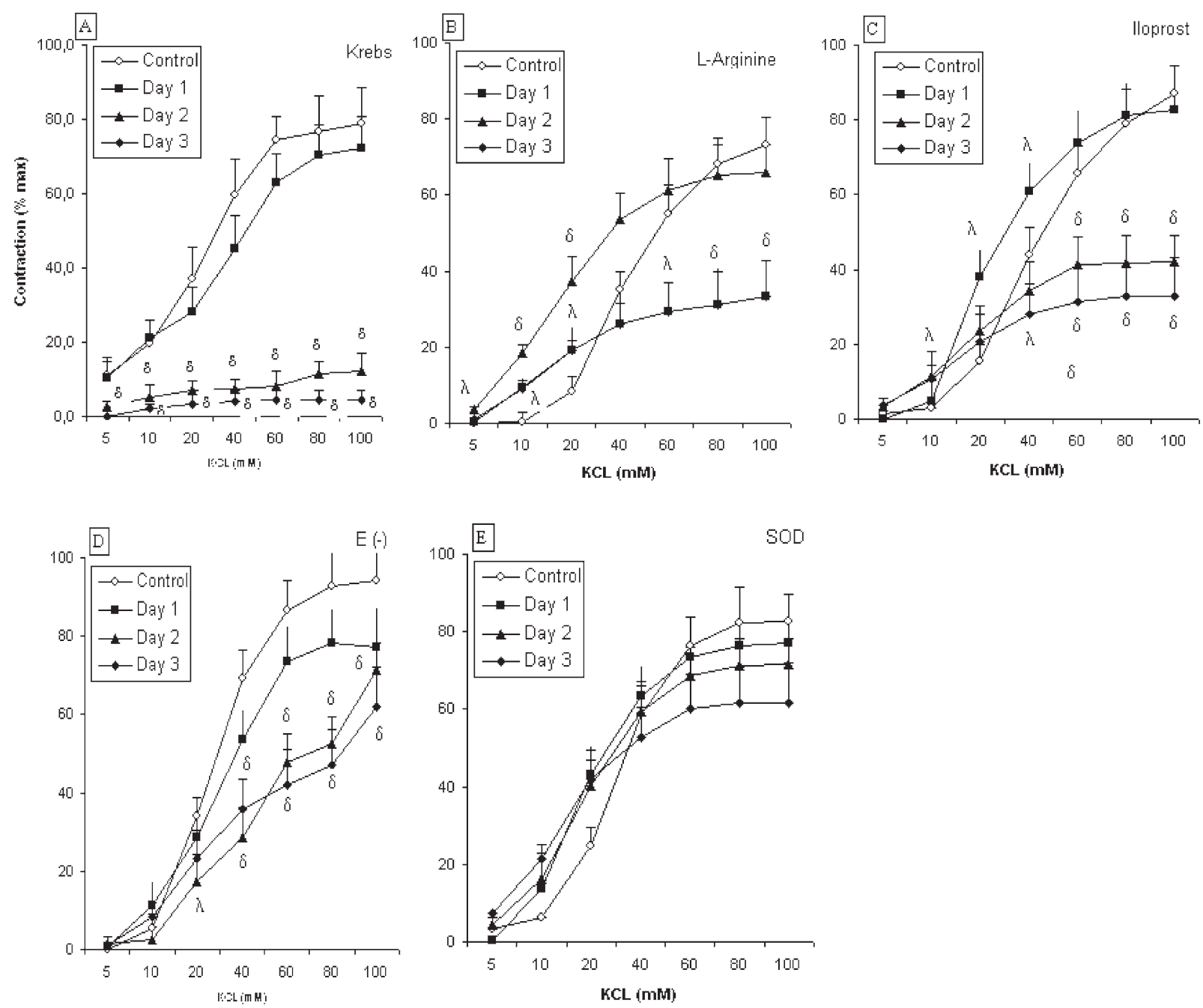

Fig. 2. Receptor independent contractions induced by potassium chloride $(\mathrm{KCl})$ in endothelium-intact rat thoracic aorta rings: Rings were stored at $4^{\circ} \mathrm{C}$ in Krebs solution (A), with L-arginine (B), with Iloprost (C), with SOD (E), and endotheliumdenuded rings in Krebs solution (D). Each point represents the average value of 8-12 experiments per day and vertical bars show SEM. The statistical analysis was performed by using the Analysis of Variance (ANOVA). $\lambda, p<0.05$ and $\delta$, $p<0.01$ : significantly different from control.

TABLE 1. Average maximum reponses to ACh $\left(1 \times 10^{-6} \mathrm{M}\right)$. Data are presented as mean \pm S.E.M. Statistical analysis was performed by using the Analysis of Variance (ANOVA) or the Kruskal Wallis ANOVA followed by Dunn or Student's Newman-Keuls test, respectively.

\begin{tabular}{lcccc}
\hline Time of preservation & Krebs & L-Arginine & SOD & Iloprost \\
\hline $\begin{array}{l}0 \mathrm{~h} \text { (fresh) } \\
(\mathrm{n})\end{array}$ & $76.9 \pm 6.1$ & $73.8 \pm 11.2$ & $95.5 \pm 2.0$ & $99.0 \pm 0.6$ \\
$24 \mathrm{~h}$ & $(15)$ & $(10)$ & $(12)$ & $(12)$ \\
$(\mathrm{n})$ & $72.6 \pm 10.3$ & $67.3 \pm 9.7$ & $84.4 \pm 4.6^{\mathrm{a}}$ & $66.1 \pm 10.1^{\mathrm{b}}$ \\
$48 \mathrm{~h}$ & $(15)$ & $(10)$ & $(11)$ & $(12)$ \\
$(\mathrm{n})$ & $45.0 \pm 15.8^{\mathrm{a}}$ & $58.0 \pm 13.3$ & $74.8 \pm 7.0^{\mathrm{b}}$ & $42.8 \pm 8.3^{\mathrm{b}}$ \\
$72 \mathrm{~h}$ & $(9)$ & $(10)$ & $(12)$ & $(12)$ \\
$(\mathrm{n})$ & $33.7 \pm 11.5^{\mathrm{b}}$ & $50.0 \pm 8.6$ & $58.7 \pm 8.4^{\mathrm{b}}$ & $7.5 \pm 3.2^{\mathrm{b}}$ \\
\hline
\end{tabular}

Significantly different from day $0\left({ }^{\mathrm{a}} p<0.05 ;{ }^{\mathrm{b}} p<0.01\right)$. 
unchanged following storage for between $3-7$ days at $4^{\circ} \mathrm{C}$ (Ito and Chiba 1985; Sinanovic and Chiba 1987a). Furthermore, no significant inhibitory effect has been reported on the responsiveness of canine intermediate auricular arteries to $\mathrm{KCl}$ and 5 - $\mathrm{HT}$ after storage at $4^{\circ} \mathrm{C}$ for $5-7$ days (Ito and Chiba 1985). In contrast to these results, there are other reports indicating that responses to $\mathrm{KCl}$ are attenuated after cold storage (Sinanovic and Chiba 1987b). The discrepancy between the present and previous findings might be due to the differences in the tissues, agonists or the design of the experiment, since in most of these studies the tissues were not aerated with $95 \% \mathrm{O}_{2}-5 \% \mathrm{CO}_{2}$ during storage or the tissues were kept at $+4^{\circ} \mathrm{C}$ for longer periods.

\section{Superoxide Dismutase}

It has been shown that the cold storage of rabbit kidneys in saline for 24 hours at $0^{\circ} \mathrm{C}$ enhances lipid peroxidation. However, the tissue SOD levels remained unaltered during the storage period (Green et al. 1986). Rewarming or reperfusing the tissues after cold storage are also potent triggers of lipid peroxidation (Magni et al. 1994). Additionally, superoxide anions have been shown to inactivate an endothelium-derived relaxing-factor (Rubanyi and Vanhoutte 1986) in the canine femoral artery. Thus, it is reasonable to expect an effect of reactive oxygen species on agonist-induced responses in such studies. In our study, SOD prevented the decline in both $\mathrm{KCl}$ and 5-HT-induced responses. It has been previously shown that superoxide anion inhibited norepinephrine-induced contractions without changing the responses to phenylephrine (Phe) or $\mathrm{KCl}$ (Wolin and Belloni 1985). This indicates that superoxide anion directly prevents the activation of norepinephrine but has no direct effect on Phe or $\mathrm{KCl}$. It has also been demonstrated that, 5-HT was able to activate nNOS (neuronal nitric oxide synthase) and lead to $\mathrm{NO}$ and reactive oxygen species is produced (Breard et al. 2007). On the other hand, the combination of a delayed hypothermia and a delayed SOD treatment significantly preserved the vascular function (Baranova et al. 2008). Thus, the effect of superoxide radical on vascular responses depends on the agonist used. In rat thoracic aorta, 5-HT induces contraction through the activation of $5-\mathrm{HT}_{2}$ receptors while $\mathrm{KCl}$ activates voltage operated calcium channels by depolarizing the cell membrane. In the present study, the decline in the responses to contractile agents acting by receptor-dependent (5-HT) and receptor-independent $(\mathrm{KCl})$ mechanisms, may imply that superoxide anion exerts its effects on post receptor mechanisms; i.e. second messengers or contractile mechanisms, rather than a direct effect of 5-HT or $\mathrm{KCl}$.

\section{L-arginine}

In the current study, the incubation of the aortic rings with L-arginine, the precursor of nitric oxide (NO), preserved the $\mathrm{KCl}$ and 5-HT induced contractile responses for 2 days, but on the third day the protective effect of L-arginine had decreased. L-arginine is the precursor for the formation of NO in vascular tissue (Moncada et al. 1989) and NO has been shown to possess an antioxidant activity (Kanner et al. 1991). It has also been reported that the incubation of rat aortic rings with L-arginine prevents the damage caused by reactive oxygen species (Gümüşel et al. 1996). In rabbit aortic endothelium damaged by oxygen free radicals, the protective role of L-arginine, it has been suggested, depends on the increased synthesis of NO (Xiong et al. 1994).

The maximum response to $\mathrm{ACh}$ remained unaltered after 24 hours storage, but progressively diminished in rings that had been stored in Krebs solution for periods of 48 and 72 hours. These results indicate that endothelium preserves its functional capacity for only 24 hours under hypothermic conditions. In aortic rings incubated with L-arginine, the ACh induced maximum response had decreased by only $33 \%$ after 72 hours of cold storage, which was not statistically significant. Thus, it can be seen that L-arginine restores the ACh-induced relaxation. It is possible that cold storage causes a reduction in the levels of L-arginine in the endothelial cells and this occurs with or without changing NO synthesis. Additionally, incubation with L-arginine restores the production of NO, thereby enhancing the antioxidant activity.

\section{Iloprost}

In the present study, iloprost was less protective than SOD and endothelium removal. Several reports have confirmed the protective role of iloprost in different models of cardiac ischemia-reperfusion injury (Ferrari et al. 1989). Treatment with iloprost has been shown to decrease SOD activity in acute myocardial ischemia in rabbit hearts (Ferrari et al. 1989) and it has previously been shown that prostacyclin analogues possess free radical scavenging activity (Arroyo et al. 1994). In the present study, it is not possible to define the exact mechanism(s) which contribute to the protective role of iloprost, but the possible mechanisms are the scavenging of superoxide anions (Fraile et al. 1994) or the membrane stabilizing effect of iloprost (Thiemermann et al. 1984). It has been shown that cold storage reduces the sensitivity of tissues to extracellular calcium and enhances the membrane resting potential (Kaiman and Shibata 1978), which causes a decline in the vascular reactivity to vasoconstrictor agents. Thus, iloprost may act by stabilizing the cellular membrane and reducing cold-storage induced vascular damage.

\section{Endothelium Removal}

In the present study, endothelium removal preserved 5-HT-induced contractions for 72 hours and partially restored $\mathrm{KCl}$-induced responses after 48 and 72 hours of preservation. It has been shown that in rat aortas endothelium removal enhances the responses to $\alpha$-adrenergic agonists (Molina et al. 1992), but does not affect KCl-induced responses (Vinet et al. 1991). There are several other reports indicating that, endothelium removal caused an 
enhancement in the maximum response of rat thoracic aorta to $\mathrm{KCl}$ (Auer and Ward 1998). It has been previously demonstrated that endothelium removal enhances the responses to 5-HT in rabbit basilar artery (Trezise et al. 1992), and rabbit saphenous ven (Valentin et al. 1996) indicating that endothelium-derived relaxing factors (EDRF) cause an inhibition in these contractile responses. It has been shown that 24 hours of ischemic storage causes endothelial dysfunction in isolated rat aorta that can be prevented by cell permeable iron chelators. This indicates the role of iron-dependent oxidative injury in the development of endothelial damage after cold storage (Radovits et al. 2008). In rat thoracic aorta, endothelium removal, produced an increase in the maximal response to norephinephrine and phenylephrine, but did not affect KCl-induced responses (Vinet et al. 1991). On the other hand, it has been shown that endothelium removal slightly reduced the responses to $\mathrm{KCl}$, but markedly augmented 5-HT-induced contractions in isolated rabbit basilar arteries. Therefore the influence of endothelium removal on 5-HT-induced contractions is the result of the loss of EDRF, but not of the endothelium-derived hyperpolarizing factor (EDHF) or cycloxoygenase products (Trezise et al. 1992). These contradictory results indicate that the influence of endothelium removal seems to depend on both the tissue and the agonist.

The increase in the agonist-induced responses after endothelium denudation is generally contributed to the absence of EDRF (MacLean et al. 1993) such as EDRF and EDHF. It has been shown that in rabbit basillary arteries, the enhancement of $\mathrm{KCl}$-induced contractions after endothelium denudation is related to the decrease in EDHF, but not in the decrease in NO or prostacyclin levels (Petersson et al. 1993). In the present study, endothelium removal is shown to be more protective on 5-HT-induced contractions than on those induced by $\mathrm{KCl}$. In rabbit, it has been shown that voltage-operated calcium channels are less sensitive to EDRF and/or intracelullar cyclic guanosin monophosphate (cGMP) levels (Collins et al. 1988a, 1988b). Thus, the discrepancy leading to the effects of $\mathrm{KCl}$ and 5-HT may depend on the difference in the sensitivity of different calcium channels. The enzymes that are likely to contribute to superoxide production in endothelium are xanthine oxidase, NADH/NADPH oxidases and NOS (Bayraktutan et al. 1998) Therefore, in the present study there may be a decrease in the amount of the superoxide radical produced after the removal of the endothelium, which may lead to theeffect that protects the vascular responses.

In conclusion, the present study demonstrates that prolonged cold storage diminishes the responses to 5-HT and $\mathrm{KCl}$ in rat aorta. Among the possible mechanisms that contribute to this, superoxide anion seems to play the major role while endothelium-derived substances also contribute to the prolonged cold storage-induced changes.

\section{References}

Arroyo, C.M., Wade, J.V., Ichimori, K. \& Nakazawa, H. (1994) The scavenging of hydroxyl radical $(\mathrm{OH})$ by a prostacyclin analogue, taprostene. Chem. Biol. Interact., 91, 29-38.

Auer, G. \& Ward, M.E. (1998) Impaired reactivity of rat aorta to phenylephrine and potassium chloride after prolonged hypoxia: role of the endothelium. J. Appl. Physiol., 85, 411-417.

Baranova, A.I., Wei, E.P., Veda, Y., Sholley, M.M., Kontos, H.A. \& Povlishock, J.T. (2008) Cerebral vascular responsiveness after experimental traumatic brain injury: the beneficial effects of delayed hypothermia combined with SOD administration. $J$. Neurosurg., 109, 502-509.

Bayraktutan, U., Draper, N., Lang, D. \& Shah, A.M. (1998) Expression of functional neutrophil-type NADPH oxidase in cultured rat coronary microvascular endothelial cells. Cardiovasc. Res., 38, 256-262.

Breard, M., Sarı, M.A., Frapart, Y., Boucher, J.L., Ducrocq, C. \& Grillon, C. (2007) The endogenous neurotransmitter, serotonin, modifies nitric oxide synthase activities. Free Radic. Res., 41, 413-423.

Billingham, M.E., Baumgartner, W.A., Watson, D.C., Reitz, B.A., Masek, M.A., Raney, A.A., Oyer, P.E., Stinson, E.B. \& Shumway, N.E. (1980) Distant heart procurement for human transplantation: Ultrastructural studies. Circulation, 62 (Suppl. I), 111-119.

Collins, P., Henderson, A.H., Lang, D. \& Lewis, M.J. (1988a) Endothelium-derived relaxing factor and nitroprusside compared in noradrenaline- and $\mathrm{K}^{+}$- contracted rabbit and rat aortae. J. Physiol., (Lond) 400, 395-404.

Collins, P., Lewis, M.J. \& Henderson, A.H. (1988b) Endotheliumderived relaxing factor relaxes vascular smooth muscle by cyclic GMP-mediated effects on calcium movements. In: Vanhoutte PM (ed) Relaxing and Contracting Factors, Clifford, Humana, pp 277-283.

Corner, J.A., Berwanger, C.S. \& Stansby, G. (2003) Preservation of vascular tissue under hypothermic conditions. J. Surg. Res., 113, 21-25.

Ferrari, R., Cargnoni, A., Curello, S., Boffa, G.M. \& Ceconi, C. (1989) Effects of iloprost (ZK 36374) on glutathione status during ischemia and reperfusion of rabbit isolated hearts. Br. J. Pharmacol., 98, 678-684.

Fraile, M.L., Conde, M.V., Sanz, L., Moreno, M.J., Marco, E.J. \& Lopez de Pablo, A. (1994) Different influence of superoxide anions and hydrogen peroxide on endothelial function of isolated cat cerebral and pulmonary arteries. Gen. Pharmac., 25, 1197-1205.

Green, C.J., Healing, G., Simpkin, S., Fuller, B.J. \& Lunec, J. (1986) Reduced susceptibility to lipid peroxidation in cold ischemic rabbit kidneys after addition of desferrioxamine, mannitol or uric acid to the flush solution. Cryobiology., 23, 358-365.

Gümüşel, B., Tel, B.C., Demirdamar, R. \& Erdemli, İ.Ş. (1996) Reactive oxygen species-induced impairment of endotheliumdependent relaxation in rat aortic rings: protection by L-arginine. Eur. J. Pharm., 306, 107-112.

Hansen, T.N., Dawson, P.E. \& Brockbank, K.G.M. (1994) Effects of hypothermia upon endothelial cells: Mechanisms and clinical importance. Cryobiology, 31, 101-106.

Hunt, C.J., Song, Y.C., Bateson, E.A. \& Pegg, D.E. (1994) Fractures in cryopreserved arteries. Cryobiology, 31, 506-515.

Ito, T. \& Chiba, S. (1985) Effects of prolonged cold storage on the responsiveness of isolated and perfused canine intermediate auricular artery. Arch. Int. Pharmacodyn. Ther., 275, 13-21.

Kaiman, M. \& Shibata, S. (1978) Effect of cold storage on the sensitivity of and calcium influx into rat, rabbit and guinea pig portal veins. Blood Vessels, 15, 217-230.

Kanner, J., Harel, S. \& Granit, R. (1991) Nitric oxide as an antioxidant. Arch. Biochem. Biophys., 289, 130-136.

Knes, J.M., Hansen, T.N., Gilligan, B., Woo, H., Mangino, M., 
Haworth, R.A. \& Southard, J.H. (2005) Loss of endotheliumdependent relaxaion in abdominal aorta preserved in a co-storage system. Transpl. Int., 17, 699-706.

MacLean, M.R., McCulloch, K.M. \& McGrath, J.C. (1993) Influences of the endothelium and hypoxia on $\alpha_{1}$ - and $\alpha_{2}$-adrenoceptor-mediated responses in the rabbit isolated pulmonary artery. Br. J. Pharmacol., 108, 155-161.

Magni, F., Panduri, G. \& Paolocci, N. (1994) Hypothermia triggers iron-dependent lipoperoxidative damage in the isolated rat heart. Free Radic. Biol. Med., 16, 465-476.

Molina, R., Hidalgo, A. \& García de Boto, M.J. (1992) Influence of mechanical endothelium removal techniques and conservation conditions on rat aorta responses. Methods Find. Exp. Clin. Pharmacol., 14, 91-96.

Moncada, S., Palmer, R.M. \& Higgs, E.A. (1989) Biosynhthesis of nitric oxide from L-Arginine. A pathway for the regulation of cell function and communication. Biochem. Pharm., 38, 1709-1715.

Murphy, J.C., Carrier, O. \& Shadi, J. (1973) Effect of temperature on responses of fresh an refrigerated perfused blood vessels. Am. J. Physiol., 225, 1187-1191.

Okada, K., Yamashita, C., Okada, M. \& Okada, M. (1995) Successful 24-hour rabbit heart preservation by hypothermic continuous coronary microperfusion with oxygenated University of Wisconsin Solution. Ann. Thorac. Surg., 60, 1723-1728.

Petersson, J., Ryman, T. \& Högestätt, E.D. (1993) Enhancement of depolarization-induced contractions after endothelium denudation is not related to an impaired production of nitric oxide or prostacyclin in the rabbit basilar artery. Acta Physiol. Scand., 149, 467-474.

Pickford, M.A., Gower, J.D., Dore, C., Fryer, P.R. \& Gren C.J. (1990) Lipid peroxidation and ultrastructural changes in rat lung isografts after single-passage organ flush and 48-hour cold storage with and without one-hour reperfusion in vivo. Transplantation, 50, 210-218.

Radovits, T., Lin, L.N., Zotkina, J., Koch, A., Rauen, U., Köhler, G., Karck, M. \& Szabo, G. (2008) Endothelial dysfunction after long-term storage in HTK organ preservation solutions; effects of iron chelators and N-alpha-acetyl-L-histidine. J. Heart
Lung Transplant., 27, 208-216.

Rubanyi, G.M. \& Vanhoutte, P.M. (1986) Superoxide anions and hyperoxia inactivate endothelium-derived relaxing factor. $\mathrm{Am}$. J. Physiol., May; 250: H822-827.

Shibata, S., Hattori, K., Sakurai, I., Mori, J. \& Fujiwara, M. (1971) Adrenergic innervation and cocaine-induced potentiation of adrenergic responses of aortic strips from young and old rabbits. J. Pharmacol. Exp. Ther., 177, 621-632.

Sinanovic, O. \& Chiba, S. (1987a) Responsiveness of skeletal muscle branches of the dog femoral artery to $\alpha$-adrenoceptor agonists before and after cold storage. Arch. Int. Pharmacodyn. Ther., 287, 146-157.

Sinanovic, O. \& Chiba, S. (1987b) Pharmacological analysis of 5-HT-induced vasoconstriction in isolated, perfused dog skeletal muscle arteries. Eur. J. Pharmacol., 143, 353-360.

Thiemermann, C., Steinhagen-Thiessen, E. \& Schrör, K. (1984) Inhibition of oxygen-centered free radical formation by the stable prostacyclin-mimetic iloprost (ZK 36 374) in acute myocardial ischemia. J. Cardiovasc. Pharmacol., 6, 365-366.

Török, J., Kristek, F. \& Mokrasova, M. (1993) Endotheliumdependent relaxation in rabbit aorta after cold storage. Eur. $J$. Pharmacol., 228, 313-319.

Trezise, D.J., Drew, G.M. \& Weston, A.H. (1992) Analysis of the depressant effect of the endothelium on contractions of the rabbit isolated basilar artery to 5-hydroxytryptamine. $\mathrm{Br}$. $J$. Pharmacol., 106, 587-592.

Valentin, J.P., Bonnafous, R. \& John, G.W. (1996) Influence of the endothelium and nitric oxide on the contractile responses evoked by $5-\mathrm{HT}_{1 \mathrm{D}}$ receptor agonists in the rabbit isolated saphenous vein. Br. J. Pharmacol., 119, 35-42.

Vinet, R., Brieva, C., Pinardi, G. \& Pena, M. (1991) Modulation of alpha-adrenergic-induced contractions by endothelium-derived relaxing factor in rat aorta. Gen. Pharmacol., 22, 137-142.

Wolin, M.S. \& Belloni, F.L. (1985) Superoxide anion selectively attenuates catecholamine-induced contractile tension in isolated rabbit aorta. Am. J. Physiol., 249, H1127-H1133.

Xiong, Y., Li, Y.J. \& Deng, H.W. (1994) Protection of 1-arginine against oxygen free radicals-injured rabbit aortic endothelium. Zhongguo Yao Li Xue Bao., 15, 119-123. 